\title{
Influence of women's decision-making autonomy on antenatal care utilisation and institutional delivery services in Nigeria: evidence from the Nigeria Demographic and Health Survey 2018
}

Chukwuechefulam Kingsley Imo*

\begin{abstract}
Background: In the context of global health priority, understanding the role of power dynamics among women as an important intervention required towards achieving optimum maternal and child health outcomes is crucial. This study examined the influence of women's decision-making autonomy on antenatal care utilisation and institutional delivery services in Nigeria.
\end{abstract}

Methods: The data for the study were derived from the 2018 Nigeria Demographic and Health Survey and comprised a weighted sample of 20,100 births in the last five years that preceded the survey among married/cohabiting childbearing women. Descriptive and analytical analyses were carried out, including frequency tables and multivariate using the binary logistic regression model.

Results: The study revealed that despite a large number of women initiating antenatal care visits before 12 weeks of pregnancy (75.9\%), far fewer numbers had at least eight antenatal care visits (24.2\%) and delivered in a health facility (58.2\%). It was established that the likelihood of having at least eight antenatal care visits was significantly increased among women who enjoyed decision-making autonomy on their healthcare (aOR: 1.24, Cl: 1.02-1.51) and how their earnings are spent (aOR: 2.02, Cl: 1.64-2.48). Surprisingly, women's decision-making autonomy on how their earnings are spent significantly reduced the odds of initiating antenatal care visits early (aOR: 0.75, Cl: 0.63-0.89). Some socioeconomic and demographic factors were observed to have a positive influence on quality antenatal care utilisation and delivery in a health facility.

Conclusion: In conclusion, women's decision-making autonomy on their healthcare and how their earnings are spent was significantly found to be protective factors to having eight antenatal care visits during pregnancy. Conversely, women's autonomy on how their earnings are spent significantly hindered their initiation of early antenatal care visits. There is a need for more pragmatic efforts through enlightenment and empowerment programmes of women to achieve universal access to quality maternal healthcare services in Nigeria.

Keywords: Decision-making, Autonomy, Antenatal care, Institutional delivery, Utilisation, Nigeria

*Correspondence: imochuksco@yahoo.com

Department of Sociology, Faculty of the Social Sciences, Adekunle Ajasin

University, P. M. B. 001, Akoko-Akungba, Ondo State, Nigeria

(c) The Author(s) 2022. Open Access This article is licensed under a Creative Commons Attribution 4.0 International License, which permits use, sharing, adaptation, distribution and reproduction in any medium or format, as long as you give appropriate credit to the original author(s) and the source, provide a link to the Creative Commons licence, and indicate if changes were made. The images or other third party material in this article are included in the article's Creative Commons licence, unless indicated otherwise in a credit line to the material. If material is not included in the article's Creative Commons licence and your intended use is not permitted by statutory regulation or exceeds the permitted use, you will need to obtain permission directly from the copyright holder. To view a copy of this licence, visit http://creativecommons.org/licenses/by/4.0/. The Creative Commons Public Domain Dedication waiver (http://creativeco mmons.org/publicdomain/zero/1.0/) applies to the data made available in this article, unless otherwise stated in a credit line to the data. 


\section{Introduction}

Generally, pregnancy and childbirth are significant events in a woman's life and her family even though they represent a period of heightened vulnerability [1]. Proper care during pregnancy and delivery, apart from being a major indicator in measuring the level of healthcare performance, delivery system and developmental indices, it is important for the well-being of both the mother and child's health. Globally, every day in 2017, preventable causes related to pregnancy and childbirth lead to the deaths of about 295,000 women, with the vast majority of these deaths (94\%) occurring in low-resource settings [2]. Between 2000 and 2017, the number of maternal deaths per 100,000 live births dropped by about $38 \%$ worldwide and remained unacceptably high in Africa [2, 3].

No doubt, quality antenatal care (ANC) services and delivery in a health facility are important interventions required during pregnancy and childbirth to achieve optimum maternal and child health. These are parts of the key strategies recommended as unique opportunities for the survival and well-being of both mother and child [4-6]. Lack of proper maternal healthcare during pregnancy and childbirth is widely acknowledged to be a major contributor to maternal and child mortality through pregnancy-related complications $[7,8]$. The World Health Organisation's (WHO) guidelines of the four-visit focused ANC (FANC) model which was developed in the 1990s, was probably observed to be associated with more perinatal deaths [9]. This led to the revision of the guidelines stressing that the recommended minimum number of ANC visits from four to eight contacts throughout the pregnancy with the first visit occurring within 12 weeks (first trimester) of gestation [10]. In sub-Saharan Africa, which Nigeria is an integral part of, improving maternal and newborn health remains a major challenge, hence leading to preventable unacceptably high levels of maternal and child deaths [8, 11]. This plausibly could be attributed to power dynamics in the family, especially women decision-making autonomy relating to the utilisation of healthcare services.

Women decision-making autonomy defined as the extent of their independence on finances, matters pertaining to their health and that of the households, and freedom to visit outside the home without having to obtain permission, is considered an important intervention for quality maternal healthcare utilisation [12]. Although, some barriers to the utilisation of maternal health services from demographic and economic backgrounds [13, 14]; socio-cultural and behavioural perspectives [15-17] have been explored. This is specifically in a patriarchal society where women lack autonomy because of financial dependence and cultural norms [18] and men holding primary power has implications for maternal and child health, especially during pregnancy and childbirth [19]. Despite previous research on women's decisionmaking power and maternal healthcare utilization in Nigeria [12, 17, 21-31], there have been no studies with a special focus on the timing of first ANC visit, number of ANC visits and institutional delivery services among married/cohabiting childbearing women. Although, there has been continued progress in ensuring universal access to healthcare services, in Nigeria, out of the 57\% of women who had at least four ANC visits for their most birth, only $39 \%$ delivered in a health facility [32].

This study, therefore, extends the previous studies by investigating the influence of women's decision-making autonomy on antenatal care utilisation and institutional delivery services among married/cohabiting childbearing women in Nigeria. Using the latest Nigeria Demographic and Health Survey (NDHS) data with a special focus on the revised WHO's recommended minimum number of at least eight ANC visits throughout the pregnancy, mark a departure of this study in terms of its national coverage from most of the previous studies on maternal health services utilization in Nigeria. The outcome of this recent scenario among married/cohabiting childbearing women is expected to provide up-to-date information, relevant policy and programmatic recommendations towards achieving sustainable development goals (SDGs).

\section{Methods}

\section{Data source and design}

The data for this study were obtained from the individual recode data file of the 2018 Nigeria Demographic and Health Survey (NDHS). The survey is a cross-sectional study and data were generated from 41,821 women aged 15-49 and 13,311 men aged 15-59. A detailed report of the data collection methods and procedures for 2018 NDHS has been published elsewhere [32]. The analyses for this study covered a weighted sample of 20,100 births in the last five years that preceded the survey among childbearing women (15-49 years) who were ever-married/living with partners. This is to improve the representativeness of the data from the group of women interviewed in the survey (i.e. 2013-2018).

\section{Variables measurements}

\section{Outcome/dependent variables}

The outcome/dependent variables for this study which was based on empirical evidence were three indicators of maternal healthcare services utilisation during pregnancy and childbirth. These include; 1) timing of first ANC, 2) the number of ANC visits and 3) facility delivery services. Information on these outcome variables was generated from the 2018 NDHS and re-categorised from their original frequency ranges in the dataset. For 
instance, the women were asked about their first ANC visits during pregnancy, and the frequency ranged from ' 0 ' to ' 10 ' months. Based on 2016 WHO's guidelines that first ANC should occur before 12 weeks of gestation (first trimester), timing of the first ANC visit during pregnancy was categorised as adequate ( $<4$ months) coded ' 1 ' and inadequate ( 4 months and above) coded ' 0 '. The second outcome variable, the number of times (visits) a pregnant woman received ANC from a healthcare provider including traditional birth attendant or ANC from a private or public health facility ranged from ' 0 ' to ' 20 ' visits and was dichotomised as quality $(8+)$ coded ' 1 ' and inadequate $(<8)$ coded ' 0 '. The WHO's up-to-date recommendation that pregnant women should have at least eight ANC visits is to maximize the benefits of ANC services and is probably associated with greater maternal satisfaction than fewer ANC visits [10]. Thus, those with any associated risk would be required to make more frequent visits to receive quality medical attention $[10,33]$. The third outcome variable which is facility delivery/place of delivery is also a dichotomous variable taking the value of ' 1 ' if the woman delivered in a health facility (delivery in public or private hospitals or health centres) and ' 0 ' if she delivered at home or any other place outside of health facility. There was no distinction made about skilled or non-skilled attendance at delivery because it is assumed that those who delivered in a health facility had skilled attendance.

\section{Explanatory variables}

The main explanatory variables were women's decisionmaking measures including the following four subjects: 1) person who usually decides on respondent's healthcare, 2) the person who usually decides on large household purchases, 3) person who usually decides how to spend respondent's earnings, and 4) the person who usually decides on visits to family or relatives. Therefore, the possible answers were respondent alone, respondent and husband/partner jointly, husband/partner alone, someone else and others. The categories were collapsed into three including 'alone' which represents decision-making autonomy, jointly and by combining the last three categories into one (husband/partner alone and others). The selection of women's decision-making variables was guided by the conceptualisation of the power of a woman to have decision-making authority, including the power to solve problems that can be creative and enabling, especially as it influences maternal healthcare services utilisation $[34,35]$.

The co-variables likely to influence ANC and institutional delivery services utilisation among women included in the analysis were their current age, educational attainment, work status, wealth quintile, place of residence and region. To make interpretation simpler and more meaningful, some variables were regrouped from their original categories in the datasets. For instance, the current age of the women: 15-24/25-34/35 + years; Educational attainment: no education/ primary/secondary or tertiary; and wealth quintile: lowest/middle/highest. The selection of the co-variables was based on empirical evidence on how they influence access to healthcare services and other aspects of life [12, 21-23, 27, 36-38].

\section{Statistical analysis}

Two levels of analyses (univariate and multivariate) were carried out in this study. At the univariate level, descriptive statistics related to the characteristics of the study population, utilisation of ANC services and place of delivery were generated through frequency. At the multivariate level, unadjusted binary logistic regression analysis was adopted to measure the bivariate relationship between the outcome variables and each of the main explanatory variables, as well as selected co-variables. The adjusted logistic regression analyses were presented and two logistic regression models (Models 1 and 2) were fitted to examine the relationship between the outcome variables and main explanatory variables. Model 1 adjusted for the main explanatory variables to measure the interaction effects of the four main explanatory variables on the outcome variables. Model 2 presented the adjusted logistic regression analysis for the main explanatory variables and selected co-variables. The essence of the two models was to examine the simultaneous interaction effects of the main explanatory variables on the outcome variables in Model 1; and the interaction effects of the main explanatory variables and selected co-variables on the outcome variables in Model 2. Measures of association between the outcome variable and explanatory variables were expressed as OR with 95\% confidence intervals (CIs). A variable with OR greater than 1.00 implied that the variable increases the likelihood of the outcome, while it is the opposite when the OR is less than 1.00. All the analyses were conducted using Stata software (version 14). Svy command in Stata was used to adjust for the complex survey design of the Demographic and Health Survey (DHS) data. Besides, the dataset was carefully checked for missing values which were excluded from the analyses and weighted with the appropriate sampling weights as per the DHS sampling scheme before the analyses.

\section{Results}

Percentage distribution of the variables of the study population sample

Table 1 showed that the largest proportion of the women belonged to those aged 25-34 years, women with no 
Table 1 Distribution of the sample characteristics, NDHS 2018

\begin{tabular}{|c|c|c|c|}
\hline & Number (\%) & & Number(\%) \\
\hline Variables & $N=20,100$ & Variables & $N=20,100$ \\
\hline Age (years) & & Decision on respondent's healthcare & \\
\hline $15-24$ & $4,790(23.8)$ & Husband/partner alone and other & $11,971(59.6)$ \\
\hline $25-34$ & $9,624(47.9)$ & Respondent and partner & $6,382(31.8)$ \\
\hline $35+$ & $5,686(28.3)$ & Respondent alone & $1,747(8.7)$ \\
\hline Educational attainment & & Decision on large household purchase & \\
\hline No education & $9,206(45.8)$ & Husband/partner alone and other & $12,580(62.6)$ \\
\hline Primary & $3,075(15.3)$ & Respondent and partner & $6,579(32.7)$ \\
\hline Secondary or higher & $7,819(38.9)$ & Respondent alone & $941(4.7)$ \\
\hline Employment status & & Decision on how to spend respondent's earnings & \\
\hline Not working & $6,496(32.3)$ & Husband/partner alone and other & $1,110(9.3)$ \\
\hline currently working & $13,604(67.7)$ & Respondent and partner & $2,416(20.3)$ \\
\hline Wealth quintile & & Respondent alone & $8,398(70.4)$ \\
\hline Lowest & $9,362(46.6)$ & Decision on visits to family or relatives & \\
\hline Middle & $4,149(20.6)$ & Husband/partner alone and other & $8,821(43.9)$ \\
\hline Highest & $6,589(32.8)$ & Respondent and partner & $8,826(43.9)$ \\
\hline Place of residence & & Respondent alone & $2,453(12.2)$ \\
\hline Urban & $6,918(34.4)$ & Timing of first ANC visit & \\
\hline Rural & $13,182(65.6)$ & $<4$ months & $11,393(75.9)$ \\
\hline Region & & 4 months and above & $3,628(24.2)$ \\
\hline North-central & $3,617(18.0)$ & Number of ANC visit & \\
\hline North-east & $4,241(21.1)$ & $<8$ times & $11,393(75.8)$ \\
\hline North-west & $6,136(30.5)$ & 8 times and above & $3,628(24.2)$ \\
\hline South-east & $2,083(10.4)$ & Place of delivery & \\
\hline South-south & $1,755(8.7)$ & Home & $11,691(58.2)$ \\
\hline South-west & $2,268(11.3)$ & Health facility & $8,409(41.8)$ \\
\hline
\end{tabular}

formal education, women who were employed, those found in the lowest wealth quintile households, women residing in rural areas and those living in the North-west geopolitical region.

Overall, the results further showed that $59.6 \%$ and $62.6 \%$ of the decisions on the women's healthcare and large household purchases respectively, were made by their husbands/partners. On the other hand, a large proportion of the women admitted having decision-making autonomy on how to spend their earnings. About $44 \%$ of the decisions on women's visits to family and relatives involved their husbands/partners. Concerning ANC utilisation and institutional delivery services, $75.9 \%$ of the women initiated their first ANC visit before the end of 12 weeks of pregnancy; $24.2 \%$ at least eight ANC visits during pregnancy and $58.2 \%$ delivered at home during their last pregnancies in the five years before the survey.

\section{Antenatal care visits and institutional delivery by women's characteristics}

Table 2 presents the results of the proportions of women who initiated their first ANC visit before 12 weeks of pregnancy, who had at least eight ANC visits and delivered in a health facility by socio-demographic and household decision-making characteristics.

\section{Timing of first ANC visit}

The results indicated that a high proportion of first ANC visits before 12 weeks of pregnancy was reported among women aged 15-24 years and 35 years or older; who had secondary/tertiary education; those who were employed; found in the highest wealth quintile households; resided in urban areas; and found in the South-west region. Considering women decision-making measures, initiating first ANC visits before 12 weeks of pregnancy was high among women who made joint decisions with partners on their healthcare $(28.8 \%)$, large household purchases (29.1\%), how to spend their earnings (31.0\%) and visits to family or relatives $(27.7 \%)$.

\section{Number of ANC visits}

The results on the number of ANC visits showed similar results recorded for socio-economic and demographic characteristics of the women and the timing of 
Table 2 Proportion of women who had first ANC visit before 12 weeks of pregnancy, adequate ANC visits and delivered in a health facility by explanatory variables, NDHS 2018

\begin{tabular}{|c|c|c|c|c|}
\hline Variable/category & $\mathrm{N}$ & Timing of first ANC visit (\%) & Number of ANC visit (\%) & $\begin{array}{l}\text { Facility } \\
\text { delivery } \\
(\%)\end{array}$ \\
\hline \multicolumn{5}{|l|}{ Age } \\
\hline $15-24$ & 4,790 & 23.7 & 12.6 & 34.1 \\
\hline $25-34$ & 9,624 & 24.6 & 20.5 & 44.4 \\
\hline $35+$ & 5,686 & 23.7 & 21.3 & 44.0 \\
\hline \multicolumn{5}{|l|}{ Educational attainment } \\
\hline No education & 9,206 & 15.9 & 4.2 & 15.2 \\
\hline Primary & 3,075 & 23.3 & 18.6 & 44.5 \\
\hline Secondary or higher & 7,819 & 30.4 & 36.1 & 72.1 \\
\hline \multicolumn{5}{|l|}{ Employment status } \\
\hline Not working & 6,496 & 20.3 & 10.1 & 29.6 \\
\hline currently working & 13,604 & 25.7 & 23.0 & 47.7 \\
\hline \multicolumn{5}{|l|}{ Wealth quintile } \\
\hline Lowest & 9,362 & 19.3 & 6.0 & 18.5 \\
\hline Middle & 4,149 & 22.8 & 18.6 & 45.6 \\
\hline Highest & 6,589 & 29.3 & 37.2 & 72.6 \\
\hline \multicolumn{5}{|l|}{ Place of residence } \\
\hline Urban & 6,918 & 25.9 & 33.0 & 63.9 \\
\hline Rural & 13,182 & 22.9 & 11.4 & 30.3 \\
\hline \multicolumn{5}{|l|}{ Region } \\
\hline North-central & 3,617 & 31.7 & 15.3 & 52.2 \\
\hline North-east & 4,241 & 19.5 & 3.9 & 25.3 \\
\hline North-west & 6,136 & 12.5 & 3.7 & 15.4 \\
\hline South-east & 2,083 & 32.5 & 39.3 & 82.0 \\
\hline South-south & 1,755 & 26.9 & 34.7 & 52.1 \\
\hline South-west & 2,268 & 32.8 & 62.3 & 82.9 \\
\hline \multicolumn{5}{|l|}{ Decision on respondent's healthcare } \\
\hline Husband/partner alone and other & 8,066 & 20.5 & 11.2 & 30.0 \\
\hline Respondent and partner & 5,481 & 28.8 & 28.4 & 60.0 \\
\hline Respondent alone & 1,474 & 26.5 & 36.3 & 56.5 \\
\hline \multicolumn{5}{|l|}{ Decision on large household purchase } \\
\hline Husband/partner alone and other & 8,676 & 20.5 & 13.0 & 31.6 \\
\hline Respondent and partner & 5,546 & 29.1 & 28.0 & 58.5 \\
\hline Respondent alone & 766 & 28.9 & 32.3 & 62.6 \\
\hline \multicolumn{5}{|c|}{ Decision on how to spend respondent's Earnings } \\
\hline Husband/partner alone and other & 784 & 27.8 & 14.5 & 39.8 \\
\hline Respondent and partner & 2,143 & 31.0 & 33.2 & 67.9 \\
\hline Respondent alone & 6,727 & 22.4 & 22.5 & 43.3 \\
\hline \multicolumn{5}{|l|}{ Decision on visits to family or relatives } \\
\hline Husband/partner alone and other & 5,847 & 19.6 & 11.3 & 28.9 \\
\hline Respondent and partner & 7,182 & 27.7 & 24.4 & 53.0 \\
\hline Respondent alone & 1,992 & 24.8 & 26.1 & 48.2 \\
\hline
\end{tabular}

first ANC visits. The proportion of women that had at least eight ANC visits was high among those who made independent decisions on their healthcare (36.3\%), large household purchases (32.3\%) and visits to family or relatives $(26.1 \%)$. On the other hand, the proportion was high among women who made joint decisions on how their earnings are spent (33.2\%). 


\section{Facility delivery}

Concerning socio-economic and demographic characteristics of the women and delivery in a health facility, similar results observed on the timing of the first ANC visit and the number of ANC visits was recorded. The results further showed that the proportion of women who delivered in a health facility was high among those who made joint decisions with partners on their healthcare $(60.0 \%)$, how to spend their earnings $(67.9 \%)$ and their visits to family or relatives (53.0\%). However, the proportion was high among women who made independent decisions on large household purchases (62.6\%).

\section{Unadjusted logistic regression analyses of the relationship between explanatory variables and antenatal care utilisation and institutional delivery services}

Table 3 presented the unadjusted logistic regression analyses was adopted to measure the bivariate relationship between the outcome variables and each of the main explanatory variables, as well as co-variables.

\section{Timing of first ANC visit}

The results of the unadjusted logistic regression analyses are presented in Table 3 indicated that all the women's decision-making variables were significant with the timing of the first ANC visit. The results showed that the likelihood of having first ANC visit before 12 weeks of pregnancy significantly increased among women who made joint decisions with partners and independent decisions on their healthcare, large household purchases and visits to family or relatives, relative to those in the reference category. On the other hand, the likelihood of having first ANC visits before 12 weeks of pregnancy significantly reduced among women who made independent decisions on how their earnings are spent (OR: 0.75; CI: 0.64-0.89). For socio-economic and demographic variables, except for age, all the other variables were significantly related to the timing of the first ANC visit.

\section{Number of ANC visits}

As observed in the timing of the first ANC visit, the results revealed that women whose husbands/partners made independent decisions on their healthcare (OR: 0.37, CI: 0.34-0.42), large household purchases (OR: 0.38, CI: $0.33-0.44$ ), how to spent their earnings (OR: $0.72, \mathrm{CI}: 0.63-0.81$ ) and visits to family or relatives (OR: 0.53, CI: 0.49-0.58) significantly reduced the odds of having at least four ANC visits. Besides, the co-variables that significantly influenced the likelihood of having at least four ANC visits included age, maternal education, employment status, household wealth quintile, place of residence, as well as region of residence.

\section{Facility delivery}

In Table 3, the results showed that women who made independent decisions and joint decisions with partners on their healthcare, large household purchases, how their earnings are spent and visits to family or relatives were significantly more likely to deliver in health facilities than their counterparts in the reference categories. All the socio-economic and demographic variables were significantly associated with delivery in a health facility.

\section{Adjusted logistic regression analyses}

The adjusted logistic regression analyses results presented in Table 4 showed some variations in the timing of the first ANC visit, the number of ANC visits and facility delivery by women's decision-making measures and selected socio-economic and demographic variables.

\section{Timing of first ANC visit}

In Model 1, the results indicated that the likelihood of initiating the first ANC visit before 12 weeks of pregnancy significantly increased among women who made independent decisions on their healthcare (aOR: 1.21, CI: 1.10-1.46) and large household purchases (aOR: 1.41, CI: 1.14-1.76). The women who made joint decisions with partners on visits to family or relatives were significantly more likely to have their first ANC visits before 12 weeks of pregnancy (aOR: 1.31, CI: 1.31-1.52) than those in the reference category. Surprisingly, the likelihood of initiating first ANC visits before 12 weeks of pregnancy was significantly reduced among women who made independent decisions on how their earnings are spent (aOR: 0.66, CI: 0.56-0.78). Similar results of the likelihood of having first ANC visits before 12 weeks of pregnancy among women who made independent decisions on how their earnings are spent were recorded after adjusting with selected socio-economic and demographic variables in Model 2. Also, women who made joint decisions with partners and those who made independent decisions on their visits to family or relatives were significantly more likely to have first ANC visits before 12 weeks of pregnancy relative to those in the reference category. The results in Model 2 further showed some variations among the selected socio-economic and demographic variables. For instance, women who were rural residents were significantly less likely to have their first ANC visits before 12 weeks of pregnancy (aOR: 0.13, CI: 0.01-0.26) than their urban counterparts. There were some differences recorded across the geopolitical regions in terms of timing of first ANC visits among the women. 
Table 3 Unadjusted logistic regression model of the association between the explanatory variables and antenatal care visits and institutional delivery, 2018 Nigeria DHS

\begin{tabular}{|c|c|c|c|}
\hline Variable/category & $\begin{array}{l}\text { Timing of first ANC visit } \\
\text { OR( } 95 \% \mathrm{Cl})\end{array}$ & $\begin{array}{l}\text { Number of ANC visit } \\
\text { OR(95\% CI) }\end{array}$ & $\begin{array}{l}\text { Facility delivery } \\
\text { OR( } 95 \% \mathrm{CI})\end{array}$ \\
\hline \multicolumn{4}{|l|}{ Decision on respondent's healthcare } \\
\hline Husband/partner alone and other (Ref.) & 1.00 & 1.00 & 1.00 \\
\hline Respondent and partner & $1.57(1.45-1.70)^{* * *}$ & $3.16(2.92-3.42)^{* * *}$ & $3.49(3.28-3.72)^{* * *}$ \\
\hline Respondent alone & $1.39(1.22-1.58))^{* * *}$ & $4.53(4.05-5.08)^{* * *}$ & $3.03(2.73-3.35)^{* * *}$ \\
\hline \multicolumn{4}{|l|}{ Decision on large household purchase } \\
\hline Husband/partner alone and other (Ref.) & 1.00 & 1.00 & 1.00 \\
\hline Respondent and partner & $1.59(1.47-1.72)^{* * *}$ & $2.60(2.41-2.80)^{* * *}$ & $3.06(2.88-3.26)^{* * *}$ \\
\hline Respondent alone & $1.57(1.34-1.85)^{* * *}$ & $3.19(2.75-3.69)^{* * *}$ & $3.63(3.16-4.16)^{* * *}$ \\
\hline \multicolumn{4}{|c|}{ Decision on how to spend respondent's Earnings } \\
\hline Husband/partner alone and other (Ref.) & 1.00 & 1.00 & 1.00 \\
\hline Respondent and partner & $1.17(0.97-1.40)$ & $2.92(2.42-3.53)^{* * *}$ & $3.20(2.76-3.71)^{* * *}$ \\
\hline Respondent alone & $0.75(0.64-0.89)^{* *}$ & $1.71(1.43-2.03)^{* * *}$ & $1.15(1.02-1.31)^{*}$ \\
\hline \multicolumn{4}{|l|}{ Decision on visits to family or relatives } \\
\hline Husband/partner alone and other (Ref.) & 1.00 & 1.00 & 1.00 \\
\hline Respondent and partner & $1.58(1.45-1.71)^{* * *}$ & $2.53(2.33-2.74)^{* * *}$ & $2.77(2.60-2.95)^{* * *}$ \\
\hline Respondent alone & $1.36(1.20-1.53)^{* * *}$ & $2.76(2.47-3.09)^{* * *}$ & $2.28(2.08-2.50)^{* * *}$ \\
\hline \multicolumn{4}{|l|}{ Age } \\
\hline $15-24$ (Ref.) & 1.00 & 1.00 & 1.00 \\
\hline $25-34$ & $1.05(0.95-1.15)$ & $1.44(1.34-1.54)^{* * *}$ & $1.55(1.44-1.66)^{* * *}$ \\
\hline $35+$ & $1.00(0.90-1.11)$ & $1.39(1.29-1.50)^{* * *}$ & $1.52(1.44-1.66)^{* * *}$ \\
\hline \multicolumn{4}{|l|}{ Educational attainment } \\
\hline No education (Ref.) & 1.00 & 1.00 & 1.00 \\
\hline Primary & $1.60(1.42-1.80)^{* * *}$ & $3.28(3.02-3.57)^{* * *}$ & $4.46(4.08-4.89)^{* * *}$ \\
\hline Secondary or higher & $2.31(2.11-2.53)^{* * *}$ & $7.89(7.35-8.47)^{* * *}$ & $14.42(13.42-15.55)^{* * *}$ \\
\hline \multicolumn{4}{|l|}{ Employment status } \\
\hline Not working (Ref.) & 1.00 & 1.00 & 1.00 \\
\hline currently working & $1.36(1.25-1.48)^{* * *}$ & $2.05(1.93-2.17)^{* * *}$ & $2.17(2.04-2.31)^{* * *}$ \\
\hline \multicolumn{4}{|l|}{ Wealth quintile } \\
\hline Lowest (Ref.) & 1.00 & 1.00 & 1.00 \\
\hline Middle & $1.24(1.11-1.37)^{* * *}$ & $2.81(2.60-3.03)^{* * *}$ & $3.68(3.40-3.99)^{* * *}$ \\
\hline Highest & $1.73(1.59-1.89)^{* * *}$ & $7.09(6.58-7.64)^{* * *}$ & $11.66(10.82-12.57)^{* * *}$ \\
\hline \multicolumn{4}{|l|}{ Place of residence } \\
\hline Urban (Ref.) & 1.00 & 1.00 & 1.00 \\
\hline Rural & $0.85(0.79-0.91)^{* * *}$ & $0.30(0.28-0.31)^{* * *}$ & $0.25(0.23-0.26)^{* * *}$ \\
\hline \multicolumn{4}{|l|}{ Region } \\
\hline North-central (Ref.) & 1.00 & 1.00 & 1.00 \\
\hline North-east & $0.52(0.46-0.59)^{* * *}$ & $0.58(0.53-0.64)^{* * *}$ & $0.31(0.28-0.34)^{* * *}$ \\
\hline North-west & $0.31(0.27-0.35)^{* * *}$ & $0.51(0.47-0.55)^{* * *}$ & $0.17(0.15-0.18)^{* * *}$ \\
\hline South-east & $1.04(0.91-1.17)$ & $4.33(3.77-4.97)^{* * *}$ & $4.18(3.67-4.75)^{* * *}$ \\
\hline South-south & $0.79(0.68-0.91)^{* * *}$ & $1.58(1.40-1.78)^{* * *}$ & $1.00(0.89-1.12)$ \\
\hline South-west & $1.05(0.93-1.18)$ & $5.76(4.98-6.67)^{* * * *}$ & $4.43(3.90-5.03)^{* * *}$ \\
\hline
\end{tabular}

Note: ${ }^{*} p<0.05 ;{ }^{* *} p<0.01 ;{ }^{* * *} p<0.001 ;$ Ref. $=$ reference category

\section{Number of ANC visits}

In Model 1, the results on having at least eight ANC visits showed almost similar patterns of the influence of women's decision-making measures. For instance, the likelihood of having at least eight ANC visits during pregnancy was significantly increased among women who made joint decisions with partners and independent decisions on their healthcare, large household 
Table 4 Adjusted logistic regression analyses of women's decision-making measures, selected co-variables and outcome variables, 2018 Nigeria DHS

\begin{tabular}{|c|c|c|c|c|c|c|}
\hline \multirow[b]{2}{*}{ Variable/category } & \multicolumn{2}{|c|}{ Timing of first ANC visit } & \multicolumn{2}{|c|}{ Number of ANC visit } & \multicolumn{2}{|l|}{ Facility delivery } \\
\hline & $\begin{array}{l}\text { Model } 1 \\
\text { aOR(95\% Cl) }\end{array}$ & $\begin{array}{l}\text { Model } 2 \\
\text { aOR(95\% Cl) }\end{array}$ & $\begin{array}{l}\text { Model } 1 \\
\text { aOR(95\% Cl) }\end{array}$ & $\begin{array}{l}\text { Model } 2 \\
\text { aOR(95\% Cl) }\end{array}$ & $\begin{array}{l}\text { Model } 1 \\
\text { aOR(95\% Cl) }\end{array}$ & $\begin{array}{l}\text { Model } 2 \\
\text { aOR(95\% Cl) }\end{array}$ \\
\hline \multicolumn{7}{|c|}{ Decision on respondent's healthcare } \\
\hline $\begin{array}{l}\text { Husband/partner alone and } \\
\text { other (Ref.) }\end{array}$ & 1.00 & 1.00 & 1.00 & 1.00 & 1.00 & 1.00 \\
\hline Respondent and partner & $1.12(0.96-1.30)$ & $0.93(0.79-1.09)$ & $1.84(1.59-2.13)^{* * *}$ & $0.90(0.76-1.08)$ & $1.84(1.63-2.09)^{* * *}$ & $1.09(0.94-1.28)$ \\
\hline Respondent alone & $1.21(1.10-1.46)^{*}$ & $0.94(0.77-1.14)$ & $2.94(2.49-3.47)^{* * *}$ & $1.24(1.02-1.51)^{*}$ & $2.24(1.93-2.60)^{* * *}$ & $1.05(0.87-1.27)$ \\
\hline \multicolumn{7}{|c|}{ Decision on large household purchase } \\
\hline $\begin{array}{l}\text { Husband/partner alone and } \\
\text { other (Ref.) }\end{array}$ & 1.00 & 1.00 & 1.00 & 1.00 & 1.00 & 1.00 \\
\hline Respondent and partner & $1.16(1.00-1.36)$ & $1.01(0.87-1.19)$ & $1.53(1.32-1.76)^{* * *}$ & $1.02(0.86-1.21)$ & $1.48(1.31-1.68)^{* * *}$ & $0.92(0.79-1.07)$ \\
\hline Respondent alone & $1.41(1.14-1.74)^{* *}$ & $1.56(0.93-1.44)$ & $1.63(1.34-1.98)^{* * *}$ & $0.87(0.69-1.08)$ & $2.10(1.74-2.53)^{* * *}$ & $1.09(0.87-1.37)$ \\
\hline \multicolumn{7}{|c|}{$\begin{array}{l}\text { Decision on how to spend respondent's } \\
\text { Earnings }\end{array}$} \\
\hline $\begin{array}{l}\text { Husband/partner alone and } \\
\text { other (Ref.) }\end{array}$ & 1.00 & 1.00 & 1.00 & 1.00 & 1.00 & 1.00 \\
\hline Respondent and partner & $0.88(0.72-1.07)$ & $0.85(0.70-1.03)$ & $1.57(1.28-1.92)^{* * *}$ & $1.61(1.29-2.01)^{* * *}$ & $1.54(1.31-1.82)^{* * *}$ & $1.09(0.96-1.24)$ \\
\hline Respondent alone & $0.66(0.56-0.78)^{* * *}$ & $0.75(0.63-0.89)^{* *}$ & $1.27(1.06-1.52)^{*}$ & $2.02(1.64-2.48)^{* * *}$ & $0.85(0.74-0.97)^{*}$ & $0.89(0.76-1.06)$ \\
\hline \multicolumn{7}{|c|}{ Decision on visits to family or relatives } \\
\hline $\begin{array}{l}\text { Husband/partner alone and } \\
\text { other (Ref.) }\end{array}$ & 1.00 & 1.00 & 1.00 & 1.00 & 1.00 & 1.00 \\
\hline Respondent and partner & $1.31(1.13-1.52)^{* * *}$ & $1.28(1.10-1.49)^{* *}$ & $1.00(0.86-1.45)$ & $0.88(0.74-1.04)$ & $1.20(1.07-1.34)^{* *}$ & $1.22(1.01-1.48)^{*}$ \\
\hline Respondent alone & 1.18(0.99-1.41) & $1.20(1.00-1.43)^{*}$ & $1.09(0.93-1.29)$ & $1.02(0.85-1.25)$ & $1.09(0.95-1.25)$ & $1.12(0.95-1.32)$ \\
\hline \multicolumn{7}{|l|}{ Educational attainment } \\
\hline No education (Ref.) & & 1.00 & & 1.00 & & 1.00 \\
\hline Primary & & $1.08(0.92-1.28)$ & & $1.55(1.28-1.88)^{* * *}$ & & $1.91(1.67-2.19)^{* * *}$ \\
\hline Secondary or higher & & $1.48(1.26-1.73)^{* * *}$ & & $2.33(1.95-2.79)^{* * *}$ & & $3.85(3.39-4.38)^{* * *}$ \\
\hline \multicolumn{7}{|l|}{ Employment status } \\
\hline Not working (Ref.) & & 1.00 & & 1.00 & & 1.00 \\
\hline currently working & & $0.89(0.70-1.13)$ & & $0.99(0.74-1.32)$ & & $0.76(0.61-0.95)^{*}$ \\
\hline \multicolumn{7}{|l|}{ Wealth quintile } \\
\hline Lowest (Ref.) & & 1.00 & & 1.00 & & 1.00 \\
\hline Middle & & $0.95(0.82-1.10)$ & & $1.60(1.35-1.88)^{* * *}$ & & $1.85(1.63-2.09)^{* * *}$ \\
\hline Highest & & $1.10(0.95-1.28)$ & & $2.10(1.79-2.46)^{* * *}$ & & $3.16(2.77-3.61)^{* * *}$ \\
\hline \multicolumn{7}{|l|}{ Place of Residence } \\
\hline Urban (Ref.) & & 1.00 & & 1.00 & & 1.00 \\
\hline Rural & & $0.13(0.01-0.26)^{*}$ & & $0.72(0.64-0.80)^{* *}$ & & $0.84(0.75-0.93)^{* *}$ \\
\hline \multicolumn{7}{|l|}{ Region } \\
\hline North-central (Ref.) & & 1.00 & & 1.00 & & 1.00 \\
\hline North-east & & $0.66(0.55-0.80)^{* * *}$ & & $0.25(0.19-0.33)^{* * *}$ & & $0.48(0.41-0.56)^{* * *}$ \\
\hline North-west & & $0.48(0.40-0.57)^{* * *}$ & & $0.29(0.23-0.35)^{* * *}$ & & $0.27(0.23-0.31)^{* * *}$ \\
\hline South-east & & $1.01(0.85-1.19)$ & & $2.14(1.81-2.54)^{* * *}$ & & $1.73(1.44-2.07)^{* * *}$ \\
\hline South-south & & $0.75(0.63-0.91)^{* *}$ & & $1.98(1.66-2.36)^{* * *}$ & & $0.41(0.35-0.48)^{* * *}$ \\
\hline South-west & & $1.12(0.96-1.31)$ & & $4.78(4.09-5.60)^{* * * *}$ & & $1.94(1.64-2.30)^{* * *}$ \\
\hline
\end{tabular}

Note: ${ }^{*} p<0.05 ;{ }^{* *} p<0.01 ;{ }^{* * *} p<0.001$; Ref. $=$ reference category 
purchases and how their earnings are spent. The results presented in Model 2 showed that the likelihood of having at least eight ANC visits was significantly reduced among women who made independent decisions on their healthcare (aOR: 1.24, CI: 1.02-1.51), those who made joint decisions joint decisions with partners (aOR: 1.61, CI: 1.29-2.01) and independent decisions (aOR: 2.02, CI: 1.64-2.48) on how their earnings are spent. The results further showed some differences regarding the influence of the selected socio-economic and demographic variables on having at least eight ANC visits among women during pregnancy.

\section{Facility delivery}

The adjusted logistic regression analysis results presented in Table 4, Model 1 showed that women who made joint decisions with partners and independent decisions on their healthcare and large household purchases were more likely to deliver in a health facility than those in the reference category. Similar results were observed among women who made joint decisions on how their earnings are spent (aOR: 1.54, CI: 1.31-1.82) and visits to family or relatives (aOR: 1.20, CI: 1.07-1.34). Surprisingly, the likelihood of delivering in a health facility was significantly reduced among women who made independent decisions on how their earnings are spent (aOR: 0.85, CI: 0.74-0.97) compared to those in the reference category. After adjusting for selected co-variables in Model 2, it was revealed that the likelihood of delivering in a health facility significantly increased among women who made joint decisions with partners on their visits to family or relatives (aOR: 1.22, CI: 1.01-1.48). The results further indicated that an increase in women's level of education and household wealth quintile increased the likelihood of delivering in a health facility. Unexpectedly, the results showed that the likelihood of delivering in a health facility significantly reduced among women who reported to be employed (aOR: 0.76, CI: 0.61-0.95). There were significant variations relating to delivery in a health facility among women by place of residence and region.

\section{Discussion}

This study examined the influence of women's decisionmaking autonomy on ANC utilisation and institutional delivery services among women in Nigeria using the 2018 NDHS survey. Using a nationally representative population sample of childbearing women who were currently married and living with partners, with a special focus on the indicators of maternal healthcare services utilisation during pregnancy and childbirth. This marks a departure in terms of its national coverage from most of the previous studies on maternal health services utilization in Nigeria.
Maternal healthcare services utilisation during pregnancy and childbirth is important to reduce preventable maternal and newborn mortality and morbidity through the management of pregnancy-related complications [39, 40]. Overall, the findings of this study revealed that while $75.6 \%$ of the women initiated first ANC visits before 12 weeks of pregnancy, $75.8 \%$ had less than eight ANC visits as against the revision of the WHO's four-visit focused ANC (FANC) model recommending the minimum number of ANC visits from four to eight contacts throughout the pregnancy. The finding on the timing of the first ANC is in contrast to the observation of a previous study in Tanzania which demonstrated that timely attendance at the ANC in the first trimester of pregnancy was low [40]. The findings further revealed that over onehalf of the women delivered their babies at home during their last pregnancies. This is an indication that initiating the first ANC visits by pregnant women within the first trimester of pregnancy, may not translate to having at least eight ANC visits and delivery in a health facility. Also, the findings on decision-making revealed that an overwhelming majority of the women enjoyed decisionmaking autonomy on how to spend their earnings, unlike on issues relating to their healthcare, large household purchases and visits to family or relatives.

The findings on the influence of women's decisionmaking measures on ANC utilisation and institutional delivery services showed that women's decision-making autonomy on their healthcare was significantly found to be a protective factor to having at least eight ANC visits during pregnancy. This corroborates a previous study in Ghana that observed women's limited autonomy creates a serious barrier to access and use maternal healthcare services [41]. In addition, the findings showed that women, who made joint decisions and independent decisions on how their earnings are spent, increased the likelihood of having at least eight ANC visits. Based on the findings on joint decision-making, in line with previous research in Bangladesh, this study establishes the significance of male partners being involved in decision-making on issues relating to maternal healthcare services as [42]. The findings further explain previous studies' observations in some countries that women's decision-making autonomy and participation increase the utilisation of maternal health services [43, 44]. Plausibly, this could be attributed to the danger of men's independent decisionmaking within the family which might make it impossible for women to have the opportunity to voice out their minds, hence influencing quality ANC utilisation and delivery in a health facility as shown in a study [45].

Surprisingly, in contrast with previous studies in Nigeria $[17,20]$ and other countries $[43,44,46-48]$, this study revealed that women's decision-making autonomy on 
how their earnings are spent was significantly found to be an inhibiting factor to initiating ANC visits early. This explains how women's perceived benefits of behavioural intentions influence the performance of such behaviours [49]. Consequently, most women who had decision-making autonomy on how to spend their earnings might be constrained to postpone early initiation of ANC visits and reduce the number of ANC visits, as well as consider delivering at home. This plausibly might be an opportunity for them to financially take care of some urgent family issues, especially in the absence of their husbands/ partners. In line with Dudgeon \& Inhorn's observation [19], this becomes inimical to policy interventions towards achieving the SDGs targets of quality and universal access to reproductive healthcare services and reducing maternal and child deaths. This is also important considering the negative impacts of the Coronavirus pandemic and socio-economic lockdown on accessing quality ANC utilisation and delivery in a health facility in Nigeria.

This study revealed that women with secondary or higher education were significantly more likely to initiate first ANC visits before 12 weeks of pregnancy. The findings further established a significantly direct influence of women's educational attainment on having at least eight ANC visits and delivering in a health facility. These corroborate the findings of previous research in some sub-Saharan African countries including Nigeria that women with higher education were more likely to be empowered in terms of knowledge about the availability and benefits of maternal health services, as well as make independent decisions regarding their health [23, 50-52]. Also, women's household wealth quintiles have significant linear relationships with having at least eight ANC visits and delivery in a health facility. No doubt, women's household wealth quintile is closely related to their educational attainment and employment status. Educated women tend to be more employed and consequently earn more income which provides them with the opportunity to have quality ANC utilization and delivery in a health facility. There is the need to introduce and encourage more women education and empowerment programmes geared towards promoting access to quality ANC utilisation and delivery in a health facility in Nigeria.

With respect to the place of residence, the findings established that the likelihood of initiating first ANC visits before 12 weeks of pregnancy, having at least eight ANC visits and delivering in a health facility was significantly reduced among women who were rural residents. The findings could be explained by the urban-rural disparity regarding peculiar characteristics such as quality educational attainment, employment status and exposure to mass media of residents, as well as the location of health centres as shown in previous studies conducted in South Africa and Guinea [53, 54]. The findings further revealed some regional variations on initiation of first ANC visits before 12 weeks of pregnancy, having at least eight ANC visits and delivery in a health facility. This validates previous observations in Nigeria that residing in a particular geographic region influenced women's ANC utilisation and institutional delivery services [22, $23,26]$. There is the need to encourage quality ANC utilisation and delivery in the health facility among pregnant women across the six geopolitical regions, especially disadvantaged regions through women empowerment programmes and region-wide sensitisations on maternal healthcare utilisation. Also, there should be more strategies towards directly engaging men in maternal health issues through couple counselling to further encourage access to quality ANC utilisation and delivery in the health facility among women. This is imperative in a country like Nigeria where there is a strong adherence to patriarchal norms and cultural perceptions of men.

The outcomes of this study have some policy implications and interventions towards achieving the SDGs targets of quality and universal access to maternal healthcare services, as well as reducing maternal and child deaths, through women empowerment programmes and region-wide sensitisations on maternal healthcare utilisation. However, there is a need for more quantitative and qualitative studies based on the disaggregation of the data between the geopolitical zones, to explore contextual and socio-cultural factors influencing ANC utilisation and institutional delivery services among childbearing women in Nigeria.

\section{Strengths and limitations of the study}

The main strengths of this study are the focus on the upto-date recommendation for ANC visits and the use of population-based data generated from the most recent Demographic and Health Survey, which is useful and ideal for future policy formulations. Also, the study used a national representative large sample and adopted rigorous analytical procedures with weighted proportions.

This study has its limitations. The use of cross-sectional DHS data meant cause-effect relationship could not be determined, and the explanatory variables were only temporal factors associated with quality ANC utilisation and institutional delivery services. There is the likelihood of reporting bias/discordance regarding decision-making autonomy within the family as the participants were only women and for the fact that it is to a large extent a subjective phenomenon. Also, the differences that exist between geopolitical regions in terms of some of the main outcome variables and explanatory variables could account for the results 
showing that despite a large number of women initiating antenatal care early, far fewer numbers delivered in a health facility. Despite these limitations, the findings are important for more strategic policies and programmes, especially for disadvantaged women concerning their decision-making powers influencing ANC utilisation and institutional delivery services which affect maternal and child health outcomes in Nigeria.

\section{Conclusion}

This study revealed that despite a large number of women initiating ANC before 12 weeks of pregnancy, far less numbers had at least eight ANC visits and delivered their babies in health facilities. It was further established that women's decision-making autonomy on their healthcare and how their earnings are spent was significantly found to be a protective factor to having at least eight ANC visits during pregnancy. Surprisingly, women's decision-making autonomy on how their earnings are spent was significantly found to be an inhibiting factor to initiating ANC early. There should be more pragmatic efforts and programmes through a community and region-based campaign involving men to optimise maternal healthcare services utilisation, especially among the disadvantaged women through enlightenment and empowerment programmes. This becomes important towards improving maternal and child health outcomes in a patriarchal society like Nigeria where most women experience unequal power in their intimate relationships with opposite-sex partners.

\footnotetext{
Abbreviations

ANC: Antenatal care; aOR: Adjusted Odds Ratio; WHO: World Health Organisation; FANC: Focused antenatal care; NDHS: Nigeria Demographic and Health Survey; NPC: National Population Commission; NPHC: National Population and Housing Census; EA: Enumeration Area; LGA: Local Government Areas; OR: Odds Ratio; DHS: Demographic and Health Survey; Cls: Confidence intervals; RC: Reference category; SDGs: Sustainable Development Goals; COVID-19: Coronavirus.
}

\section{Acknowledgements}

The author is grateful to the ICF International for making DHS datasets publicly available that made this study possible.

\section{Author's contributions}

CKI: Conceptualization and design of the study; accessed and used the dataset, literature review, statistical analysis and interpretation, drafting the manuscript, revision for intellectual input, read and approved the final manuscript.

\footnotetext{
Author's information

CKI is a Lecturer in the Department of Sociology, Adekunle Ajasin University, Ondo State Nigeria, where he teaches and supervises both undergraduate and postgraduate students. He bagged his PhD from the University of Ibadan, Nigeria. He was a Postdoctoral Research fellow in the Demography and Population Studies programme at the University of the Witwatersrand, Johannesburg, South Africa. CKI has special interests in Maternal and Child Health and Sexual and Reproductive Health Behaviour.
}

Funding

Not applicable.

\section{Availability of data and materials}

The NDHS 2018 individual recode dataset was used for this study and is freely available from the DHS Program archive at https://www.dhsprogram.com/ data/dataset.

\section{Declarations}

\section{Ethics approval and consent to participate}

This study utilized a secondary dataset with all personally identifiable information removed. Hence, confidentiality and anonymity are guaranteed. All methods were performed following the relevant guidelines and regulations. The survey protocol was reviewed and approved by the National Health Research Ethics Committee of Nigeria (NHREC) and the ICF Institutional Review Board. This paper was extracted from a large study for which permission to download and use the NDHS data was obtained from Measure DHS/ICF International, USA. Therefore, no further ethics approval was required.

\section{Consent for publication}

Not applicable.

\section{Competing interests}

Not applicable.

Received: 13 March 2021 Accepted: 15 February 2022

Published online: 21 February 2022

\section{References}

1. World Health Organisation (WHO): Maternal mortality fact sheets 2018. Available: https://www.who.int/news-room/facts-sheets/detail/maternalmortality.

2. UN IGME. Levels \& Trends in Child Mortality: Report 2020, Estimates developed by the United Nations Inter-agency Group for Child Mortality Estimation, United Nations Children's Fund, New York. URL: https://www. unicef.org/media/79371/file/UN-IGME-child-mortality-report-2020.pdf.

3. United Nations Children's Fund: Maternal mortality. UNICEF 2017. http:// data.unicef.org/topic/maternal-health/maternal-mortality.

4. Adjiwanou V, Legrand T. Does antenatal care matter in the use of skilled birth attendance in rural Africa: a multi-country analysis. Soc Sci Med. 2013;86:26-34.

5. Lambon-Quayefio MP, Owoo NS. Examining the influence of antenatal care visits and skilled delivery on neonatal deaths in Ghana. Appl Health Econ Health Policy. 2014;12:511-22.

6. Singh A, Pallikadavath S, Ram F, Alagarajan M. Do antenatal care interventions improve neonatal survival in India? Health Policy Plan. 2014:29:842-8.

7. Friberg IK, Kinney MV, Lawn JE, Kerber KJ, Odubanjo MO, Bergh A, et al. Sub-Saharan Africa's mothers, newborns, and children: how many lives could be saved with targeted health interventions? PLoS Med. 2010; $7(6): e 1000295$

8. Kinney MV, Kerber KJ, Black RE, Cohen B, Nkrumah F, Coovadia H, et al. Sub-Saharan Africa's mothers, newborns, and children: where and why do they die? PLoS Med. 2010;7(6):e1000294.

9. World Health Organization (WHO). WHO antenatal care randomized trial: manual for the implementation of the new model. 2002 WHO. https:// apps.who.int/iris/handle/10665/42513

10. World Health Organization (WHO). Who recommendations on antenatal care for a positive pregnancy experience, 2016 Geneva. http://apps.who. int/iris/bitstream/10665/250796/1/9789241549912-eng. pdf.

11. Zureick-Brown S, Newby H, Chou D, Mizoguchi N, Say L, Suzuki E, et al. Understanding global trends in maternal mortality. Int Perspect Sex Reprod Health. 2013;39:32-41.

12. Aliyu AA, Dahiru T. Predictors of delayed antenatal care (Anc) visits in Nigeria: secondary analysis of 2013 Nigeria demographic and health survey (NdhS). Pan Afr Med J. 2017;26:124. 
13. McNamee $P$, Ternent $L$, Hussein J. Barriers in accessing maternal healthcare: evidence from low-and middle-income countries. Expert Rev Pharmacoecon Outcomes Res. 2009;9:41-8.

14. Amin R, Shah NM, Becker S. Socioeconomic factors differentiating maternal and child health-seeking behaviour in rural Bangladesh: a cross-sectional analysis. Int J Equity Health. 2010;9:9.

15. Islam N, Islam MT, Yoshimura Y. Practices and determinants of delivery by skilled birth attendants in Bangladesh. Reprod Health. 2014;11:86.

16. Deo KK, Paudel YR, Khatri RB, Bhaskar RK, Paudel R, Mehata S, et al. Barriers to utilization of antenatal care services in Eastern Nepal. Public Health Front. 2015;3:197. https://doi.org/10.3389/fpubh.2015.00197.

17. Akeju DO, Oladapo OT, Vidler M, Akinmade AA, Sawchuck D, Qureshi R, et al. Determinants of healthcare seeking behaviour during pregnancy in Ogun State, Nigeria. Reprod Health. 2016;13(Suppl 1):32.

18. Kuhnt J, Vollmer S. Antenatal care services and its implications for vital and health outcomes of children: evidence from 193 surveys in 69 low-income and middle-income countries. BMJ Open. 2017;7(11):e017122.

19. Dudgeon MR, Inhorn MC. Men's influences on women's reproductive health: medical anthropological perspectives. Soc Sci Med. 2004;59:1379-95.

20. Babalola S, Fatusi A. Determinants of use of maternal health services in Nigeria - looking beyond individual and household factors. BMC Pregnancy Childbirth. 2009;9:43.

21. Ononokpono DN, Azfredrick EC. Intimate partner violence and the utilization of maternal health care services in Nigeria. Health Care Women Int. 2014;35:973-89.

22. Fagbamigbe AF, Idemudia ES. Wealth and antenatal care utilization in Nigeria: policy implications wealth and antenatal care utilization in Nigeria: policy implications. Health Care Women Int. 2016;38:17-37.

23. Adewuyi EO, Auta A, Khanal V, Bamidele OD, Akuoko CP, Adefemi K, et al. Prevalence and factors associated with underutilization of antenatal care services in Nigeria: a comparative study of rural and urban residences based on the 2013 Nigeria demographic and health survey. PLoS One. 2018;13(5):e0197324.

24. Akinyemi JO, Afolabi RF, Awolude OA. Patterns and determinants of dropout from maternity care continuum in Nigeria. BMC Pregnancy Childbirth. 2016;16:282.

25. Kuuire VZ, Kangmennaang J, Atuoye KN, Antabe R, Boamah SA, Vercillo S, et al. Timing and utilisation of antenatal care service in Nigeria and Malawi. Glob Public Health. 2017;12:711-27.

26. Omer K, Afi NJ, Baba MC, Adamu M, Malami SA, Oyo-Ita A, et al. Seeking evidence to support efforts to increase use of antenatal care: a cross-sectional study in two states of Nigeria. BMC Pregnancy Childbirth. 2014;14:380

27. Akinyemi JO, Bamgboye EA, Ayeni O. Trends in neonatal mortality in Nigeria and effects of bio-demographic and maternal characteristics. BMC Pediatr. 2015;15:36

28. Ahuru RR. The influence of women empowerment on maternal and childcare use in Nigeria. Int J Healthc Manag. 2019. https://doi.org/10.1080/ 20479700.2019.1688505

29. Obasohan PE, Gana P, Mustapha MA, Umar AE, Makada A, Obasohan DN Decision making autonomy and maternal healthcare utilization among Nigerian women. Int J MCH AIDS. 2019;8:11-8.

30. Obasohan PE, Gana P, Mustapha MA, Umar AE, Makada A, Obasohan DN. Decision making autonomy and maternal healthcare utilization among Nigerian Women. Int J MCH AIDS. 2019;8(1):11-8. https://doi.org/10.21106/ ijma.264.PMID:31049260:PMCID:PMC6487508.

31. Awoleye AF, Chima V, Alawode OA. Women autonomy and maternal healthcare services utilization among young ever-married women in Nigeria. Int J Nurs Midwifery. 2018;10(6):62-73.

32. National Population Commission (NPC) \& ICF International: Nigeria Demographic and Health Survey 2018.Abuja, Nigeria, and Rockville, Maryland, USA: NPC and ICF 2019.

33. Villar J, Ba'aqeel H, Piaggio G, Lumbiganon P, Miguel BJ, Farnot U, et al. WHO antenatal care randomized trial for the evaluation of a new model of routine antenatal care. Lancet. 2001;357:1551-64.

34. Ghose B, Feng D, Tang S, Yaya S, He Z, Udenigwe O, Ghosh S, et al. Women's decision-making autonomy and utilisation of maternal healthcare services: results from the Bangladesh Demographic and Health Survey. BMJ Open. 2017;7(9):e017142. https://doi.org/10.1136/bmjopen-2017-017142.

35. Mosedale S. Assessing women's empowerment: towards a conceptual framework. J Int Dev. 2005;17(2):243-57.
36. Gebre $\mathrm{E}$, Worku A, Bukola F. Inequities in maternal health services utilization in Ethiopia 2000-2016: magnitude, trends, and determinants. Reprod Health. 2018:15:119.

37. Yaya S, Bishwajit G, Shah V. Wealth, education and urban-rural inequality and maternal healthcare service usage in Malawi. BMJ Glob Health. 2016;1(2):e000085. https://doi.org/10.1136/bmjgh-2016-000085.

38. Haruna-Ogun OA. Geographical differentials in uptake of antenatal care services in Nigeria. Health Care Women Int. 2018;39:34-49.

39. Bhutta Z, Das J, Bahl R, Lawn J, Salam R, Paul V, Sankar M, et al. Can available interventions end preventable deaths in mothers, newborn babies, and stillbirths, and at what cost? Lancet. 2014;384(9940):347-70. https://doi.org/ 10.1016/S0140-6736(1014)60792-60793.

40. Konje ET, Magoma MTN, Hatfield J, Kuhn S, Sauve RS, Dewey DM. Missed opportunities in antenatal care for improving the health of pregnant women and newborns in Geita district Northwest Tanzania. BMC Pregnancy Childbirth. 2018;18:394. https://doi.org/10.1186/s12884-018-2014-8.

41. Ganle JK, Obeng B, Segbefia AY, Mwinyuri V, Yeboah JY, Baatiema L. How intra-familial decision-making affects women's access to, and use of maternal healthcare services in Ghana: a qualitative study. BMC Pregnancy Childbirth. 2015;15:173. https://doi.org/10.1186/s12884-015-0590-4.

42. Moinuddin M, Christou A, Hoque DME, Tahsina T, Salam SS, Billah SM, Kup-pens $L$, et al. Birth preparedness and complication readiness (BPCR) among pregnant women in hard-to-reach areas in Bangladesh. PLoS ONE. 2017;12(12): e0189365. https://doi.org/10.1371/journal.pone.0189365.

43. Tekelab T, Chojenta C, Smith R, Loxton D. Factors affecting utilization of antenatal care in Ethiopia: a systematic review and meta-analysis. PLoS One. 2019;14(4):e0214848. https://doi.org/10.1371/journal.pone.0214848.

44. Hou X, Ma N. The effect of women's decision-making power on maternal health services uptake: evidence from Pakistan. Health Policy Plan. 2013;28:176-84

45. Rominski DS, Gupta M, Aborigo R, Adongo P, Engman C, Hodgson A, Moyer C. Female autonomy and reported abortion-seeking in Ghana West Africa. Int J Gynecol Obstet. 2014. https://doi.org/10.1016/j.ijgo.2014.03.031.

46. Tesfaye G, Loxton D, Chojenta C, Semahegn A, Smith R. Delayed initiation of antenatal care and associated factors in Ethiopia: a systematic review and meta-analysis. Reprod Health. 2017;14:150.

47. Story WT, Burgard SA. Couples' reports of household decision-making and the utilization of maternal health services in Bangladesh. Soc Sci Med. 2012;75:2403-11.

48. Thapa DK, Niehof A. Women's autonomy and husbands' involvement in maternal healthcare in Nepal. Soc Sci Med. 2013;93:1-10.

49. Ajzen I. The theory of planned behaviour. Organ Behav Hum Decis Process. 1991;50:179-211.

50. Bayou YT, Mashalla YS, Thupayagale-Tshweneagae G. The adequacy of antenatal care services among slum residents in Addis Ababa Ethiopia. BMC Pregnancy Childbirth. 2016;16:142. https://doi.org/10.1186/ s12884-016-0930-z

51. Ochako R, Gichuhi W. Pregnancy wantedness, frequency and timing of antenatal care visit among women of childbearing age in Kenya. Reprod Health. 2016;13:51. https://doi.org/10.1186/s12978-016-0168-2.

52. Kalule-Sabiti I, Amoateng AY, Ngake M. The effect of socio-demographic factors on the utilization of maternal health care services in Uganda. Afr Pop Stud. 2014;28(1):515-25.

53. Worku EB, Woldesenbet SA. Factors that influence teenage antenatal care utilization in John Taolo Gaetsewe (JTG) district of Northern Cape Province, South Africa: Underscoring the need for tackling social determinants of health. Int J MCH AIDS. 2016;5(2):134-45.

54. Ahinkorah BO, Seidu AA, Agbaglo E, Adu C, Budu E, Hagan JE, SchackT, et al. Determinants of antenatal care and skilled birth attendance services utilization among childbearing women in Guinea: evidence from the 2018 Guinea Demographic and Health Survey data. BMC Pregnancy Childbirth. 2021;21:2. https://doi.org/10.1186/s12884-020-03489-4.

\section{Publisher's Note}

Springer Nature remains neutral with regard to jurisdictional claims in published maps and institutional affiliations. 